Ethiopian Journal of Environmental Studies \& Management 9(Suppl. 2): 938 - 950, 2016.

ISSN: 1998-0507

Submitted: March 16, 2016

doi: http://dx.doi.org/10.4314/ejesm.v9i2.1S

Accepted: December 09, 2016

\title{
AN ASSESSMENT OF PRESENT THREATS AND ASSOCIATED CONSERVATION IMPLICATION TO THE OBAN DIVISION FOREST CROSS RIVER NATIONAL PARK; NIGERIA'S BIODIVERSITY HOTSPOT
}

*AGALD0, J.A., ${ }^{1,2}$ GWOM, T.G. ${ }^{1}$ AND APEVERGA, P.T. ${ }^{1,3}$

${ }^{1}$ A P Leventis Ornithological Research Institute, Department of Zoology University of Jos, P.M.B 2084 Jos, Nigeria

${ }^{2}$ School of Biological Science, University Of Canterbury, 20 Kirkwood Ave, Upper

Riccarton, Christchurch 8041 New Zealand

${ }^{3}$ Department of Zoology, Federal University Dutse Ibrahim Aliyu Way Bypass,

Dutse, Nigeria

\begin{abstract}
In recent years the Oban Division of Cross River National Park has received little research attention on its conservation status and species composition. It is known to be one of the most biodiversity-rich protected areas in West Africa. Hence current knowledge of its status is necessary for making informed management decisions for the continuous and improved protection of the area. This study sought to provide recent information on the conservation status of the area and its species. We used reconnaissance survey to assess present threats associated with the area and related this to encounter rate of faunal species in the area. Thirteen potential present threats to the area and its species were recognized. The encounter rate of primate species was 0.373 per $\mathrm{km}^{2}$, while mammals and large birds had an encounter rate of $1.148 \mathrm{~km}^{2}$ and $1.234 \mathrm{~km}^{2}$ respectively. Low encounter rates of these faunal groups suggests their population is declining in the area. Hence protection measures need to be improved in this important remaining forest in Nigeria to protect its species from continuous decline and its integrity as Nigeria's biodiversity hot spot.
\end{abstract}

Key Words: Biodiversity, Conservation, Hotspot, Hunting, Threats.

\section{Introduction}

Animals and plant species, and so overall levels of biodiversity, are generally exposed to a variety of human induced threats (Ajayi, 2004) that are directly or indirectly detrimental to their long term survival (Ajayi, 2004; Sechrest and Brooks, 2002). Terrestrial ecosystems, in particular, which are home to lots of species, suffer habitat destruction and degradation in a variety of ways (Sechrest and Brooks, 2002). Moreover, within terrestrial ecosystems, tropical forests suffer the most threat (Bowles et al., 1998), This, in turn, affects the high level of biodiversity

*Corresponding Author: Agaldo, J.A.

Email: arubemi@yahoo.com 
which they support (Corlett and Primark, 2010; Secretariat of the Convention on Biological Diversity, 2010).

Monitoring of threats and population status of species are recognized as an important element for effective conservation management to conserve biodiversity (Parrish et al., 2003). This requires scientific based methods that measure biodiversity and threat status with the objective to inform successful conservation decisions and actions (Parrish et al., 2003) and so to ultimately enhance recovery of the threatened species. Monitoring of populations faunal species is required in many areas where there are perceived conservation problems, and this is particularly true in rapidly developing countries with potentially failing levels of protection for key areas. This is applies particularly to the limited area of remaining tropical rainforest within Nigeria.

The Oban Division (Oban) of the Cross River National Park (CRNP) is a protected area that is part of the remaining primary forest of Nigeria. It is the largest area of pristine and continuous tropical forest block in Nigeria (BirdLife, 2012; Eniang et al., 2008). This area is an integral part of the biodiversity hotspots that exists within the Gulf of Guinea (Myers et al., 2002). It is known for its high species richness as well as endemism (Oates et al., 2004).

National parks and protected areas are faced with increasing threats such as species extinction, invasive species, habitat fragmentation and degradation which affects their ecological integrity (Aguirre et al., 2002). The Oban is said to be highly threatened because it is exploited by illegal anthropogenic activities such as logging, slash and burn farming and poaching activities (BirdLife, 2012). This is due to certain factors such as population increase, hard economic conditions (Eniang et al., 2008) and level of enforcement of protection laws in the area. Consequently, the relative abundance of species of high conservation interest, such as the Nigeria-Cameroon chimpanzee Pan trogolydes ellioti, African Forest Elephant Loxodonta cyclotis, Red-rumped putty-nosed monkey Cercopithecus nictitansludio, the African Grey Parrots Psittacus erithacus among many others is thought to be low.

Despite its high biodiversity and the apparent threats, there has been little research or monitoring of the Oban (Demey et al., 2003; Oates et al., 2002). Recently casual observations from scientists, members of local communities and park rangers have suggested that there has been a massive decline in the rate of encountering once commonly seen faunal species within most of the areas. This study sought to identify the present threats in the Oban Division CRNP by:

1. assessing and prioritizing the present threats in the Oban

2. identifying sub-divisions of the park associated with the highest amount of threats

3. and relating the threats to relative abundance of faunal species encountered

\section{Study Area}

The Oban Division of (CRNP) is one of the forests in West Africa known to be part of the gulf of guinea biodiversity hotspots of conservation concern (Myers et al., 2002). It covers an area of $2800 \mathrm{~km}^{2}$. (Latitudes $5^{\circ} 15^{\prime}$ and $5^{\circ} 25^{\prime} \mathrm{N}$; Longitudes $8^{\circ} 30^{\prime}$ and $8^{\circ} 45^{\prime} \mathrm{E}$ ). It makes up a core of the larger zone of the Cross 
River National Park (CRNP) which also borders the Korup National Park (KNP) Cameroon. Itis part of the region thought to have the last stronghold of a significant portion of pristine tropical forest in Nigeria and said to be the most diverse protected forest in West Africa (Eniang et al., 2008).

The vegetation type is described as lowland and submontane rainforest which has an annual rainfall of $3000 \mathrm{~mm}$, elevation ranging from $200 \mathrm{~m}-1000 \mathrm{~m}$ and temperature range of $23^{\circ} \mathrm{C}-37^{\circ} \mathrm{C}$. The forest is known for its species richness as well as home to some endemic species of conservation priority. It is one of the most ornithologically diverse sites in Nigeria and home to over 350 bird species. Hence it is one of the Important Bird Areas (IBA) in the country (BirdLife, 2012). The area is surrounded by about 25 villages and enclave communities and a few of the enclave communities are situated within the boundaries of the National Park.

The IUCN considers the Oban Hills, part of the Oban as an Exceptional Priority Site for biodiversity conservation as well as endemic species of conservation concern such as the NigeriaCameroon chimpanzee (Oates et al., 2008; Morgan et al., 2011).

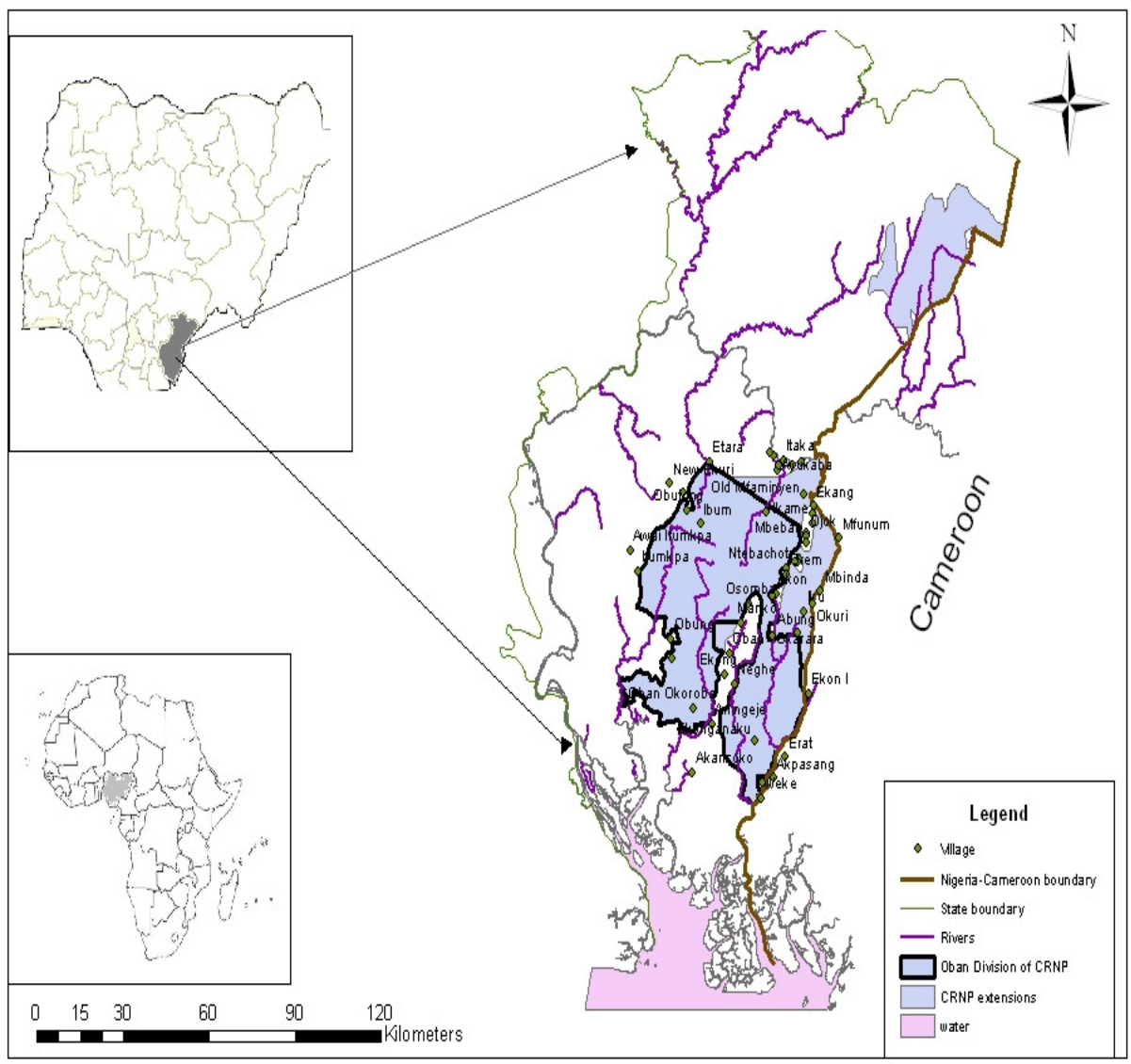

Figure 1: Map of Oban Division Cross River National Park 


\section{Methods}

\section{Survey Technique}

The guided reconnaissance "recce" walks survey method was used. This is based on the line transect survey method, and it is considered more informative than the travel "recce" which is a random walk that allows deviation of any degree (Kühl et al., 2008). Recce walks taken were a linear foot survey along predetermined compass bearing with deviations from the line of less than $40^{\circ}$. During the survey, deviations from predetermined directions were kept to a minimum except when terrain or vegetation made it impossible to continue in a straight line. When difficult terrain was encountered such as rivers and vegetation requiring large deviations (> $40^{\circ}$ ), a transect walk was ended and another begun.

Recce walks were strategically carried out using 11 communities situated within, eastern and western Oban to access the different parts of the area.

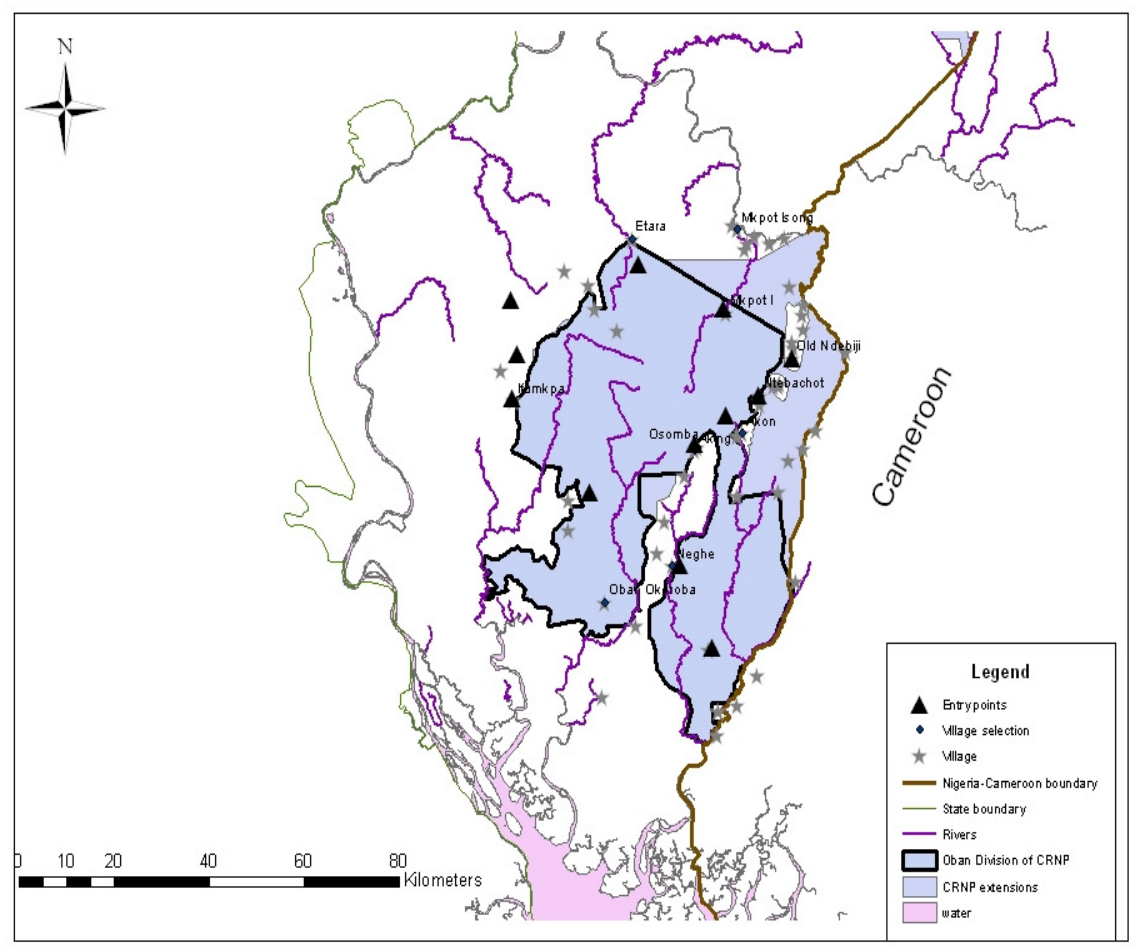

Figure 2: Map of Oban showing survey access routes (entry points)

\section{Data Collection}

Data was collected between the period of September 2011 and March 2012. A total of 36 recce paths (of total length $175.34 \mathrm{~km}$ ) with the shortest distance of $2 \mathrm{~km}$ and longest $11.4 \mathrm{~km}$ at an average speed of $1 / 2 \mathrm{~km} / \mathrm{h}$ were accessed.
A pair of binoculars was used to observe species away from the recce path and a GPS GARMIN 60Cs and GPS GARMIN Map 60 CSx were used to measures distances of recce paths walked.

Along each walk, all mammals and primates and large birds (which includes 
Hornbill, Turacos, Parrots and Guinea fowls) and their signs (sighted, calls, dung, nest, foot prints/trails) observed were recorded. All evidence of human activities heard and observed was recorded.

\section{Data Analysis}

Data was compiled using the Microsoft Excel 2007 spread sheets and analyzed a using $\mathrm{R}$ version 2:15.0

Encounter rate of identified threats was calculated using Microsoft Excel 2007

The Principal component analysis (PCA1) was used to investigate the association between the identified threats variables.

One-way analysis of variance (ANOVA) was used to compare over all disturbance between the different axis which are the eastern and western part (Oban East and West) of the Oban Division as well as the threat variables with encounter rates $>0.5 \mathrm{~km}^{2}$. Linear models were used to identify threats which have a significant effect on total encounter rate of faunal species and species abundance.

\section{Results}

Identified threats to the Oban Hills Forest

Thirteen threats were identified from anthropogenic activities in the Oban forest division of CRNP and are summarized in Table1 below;

Table 1: Identified threats and encounter rates

\begin{tabular}{llll}
\hline S/n & Disturbance variable & $\begin{array}{l}\text { Number } \\
\text { encountered }\end{array}$ & Encounter rate $\left(\mathrm{km}_{2}\right)$ \\
\hline 1 & Farms & 118 & $0.673^{*}$ \\
2 & Logged wood & 127 & $0.724^{*}$ \\
3 & Non Timber Forest Product & 26 & 0.148 \\
& (NTFP) collection & & \\
4 & Chainsaw heard & 14 & 0.079 \\
5 & Poachers shed & 13 & 0.074 \\
6 & Bush meat (Animal Carcasses ) & 16 & 0.091 \\
7 & Trails (foot/tractor) & 75 & 0.428 \\
8 & Individuals encountered & 70 & 0.399 \\
9 & Fuel wood collection & 14 & 0.078 \\
10 & Spent Cartridges & 164 & $0.935^{*}$ \\
11 & Gun shots & 8 & 0.046 \\
12 & snares & 160 & $0.912^{*}$ \\
13 & Other(Evidence of human & 15 & 0.085 \\
& presence) & & \\
& TOTAL & 820 & 4.676 \\
\hline
\end{tabular}

Encounter rate $>0.5 \mathrm{~km}^{2}$ with asterisk.

Principal component analysis (PCA) shows that certain disturbance variables show an association to each other (Figure 3). 


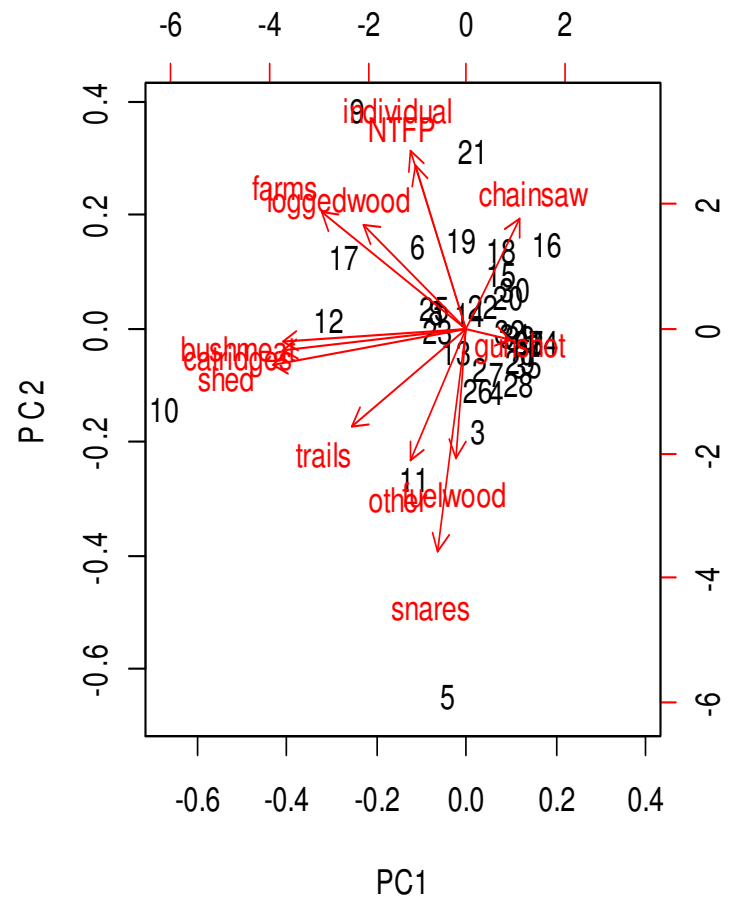

Figure 3: Principal Component Analysis 1

As shown in figure 3, bush meat (carcass encountered), shed (poacher's camp) and cartridges (spent cartridges) shows an association with each other, farms and logged wood showed an association with each other, Individuals (encountered) showed association with NTFP (signs of harvesting of NonTimber Forest Product), and snare and fuel wood collection showed an association with each other. Variables such as trails, gunshots and chainsaw heard did not show a clear-cut association with other disturbance variables. Overall threats to the Oban division differed significantly between Oban East and the western part Oban West of divisions of CRNP (Figure 4). 


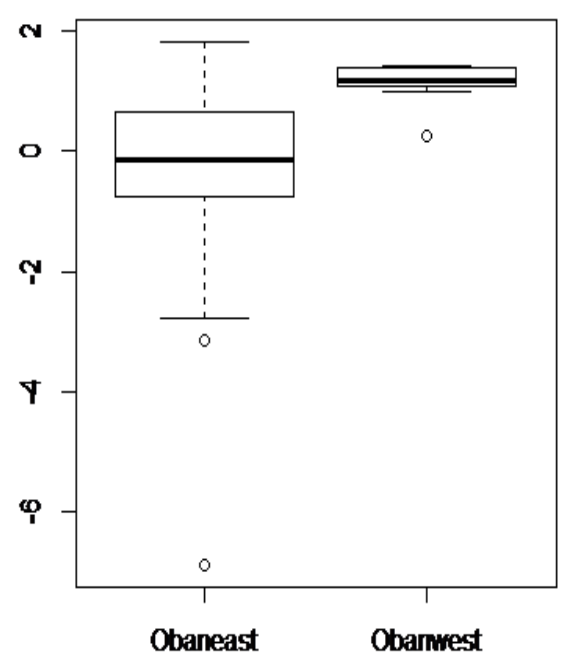

Figure 4: Disturbance rate between Oban East and West

However, some of these identified threats were similar while some had a wide variation when compared on an individual level between the two axis (Figure 5).
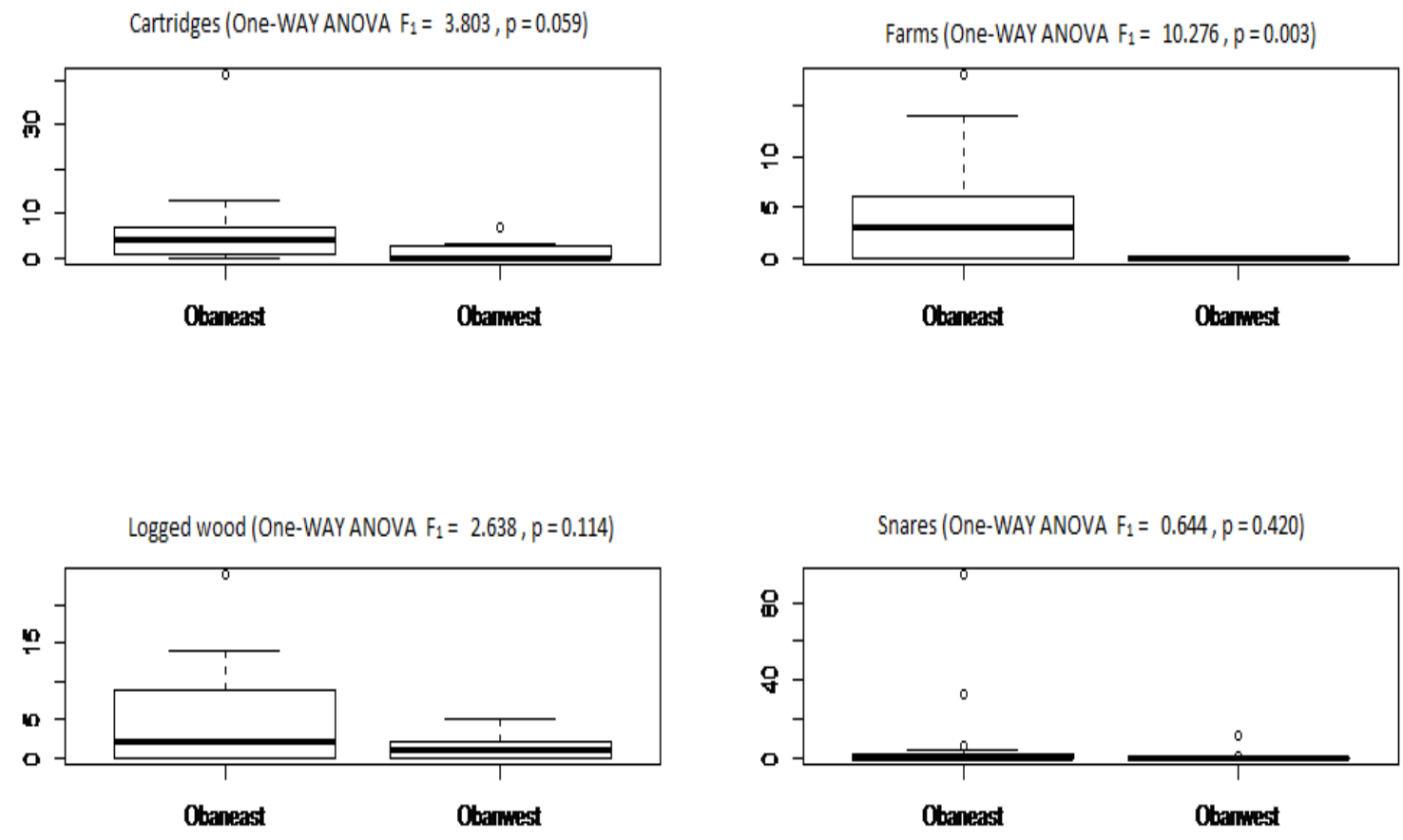

Figure 5: Cartridges, Farms, Logged wood and Snares compared between Oban East and Oban west.

Faunal species encounter rate between Oban East and Oban West did not differ (Figure 6). 


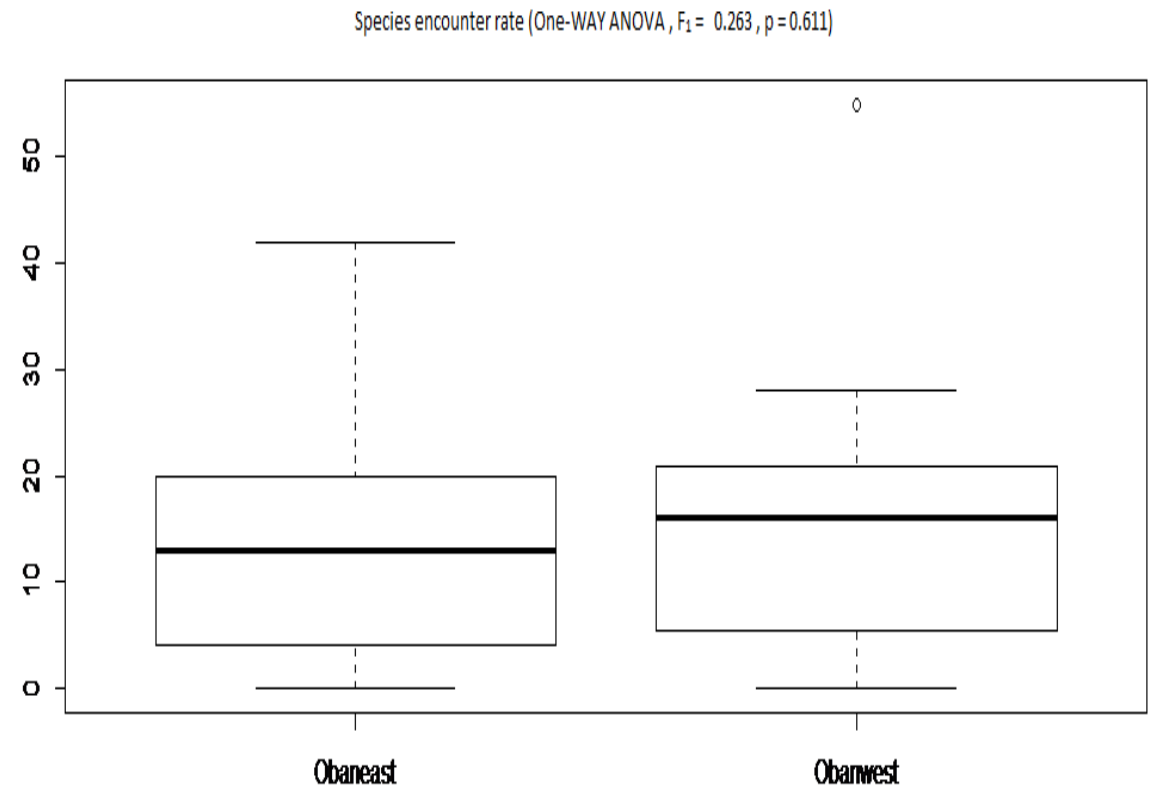

Figure 6: Species encounter rate between Oban East and Oban West.

\section{Encounter Rate of Faunal Species Groups}

The overall encounter rate of faunal species/signs was $2.833 \mathrm{~km}^{2}$. The encounter rate of primate species was $0.373 \mathrm{~km}^{2}$ and mammals, reptiles and large birds (hornbill, turacos, and parrots) had $1.148 \mathrm{~km}^{2}, 0.021 \mathrm{~km}^{2}$ and $1.234 \mathrm{~km}^{2}$ respectively.

\section{Effect of Identified Threats on Species Number and Encounter Rate}

Some identified threats had a significant effect on the overall encounter rate of faunal species in the Oban Division of the CRNP (Overall model R $\left.{ }_{2}=0.40 \mathrm{df}=32, \mathrm{p}<0.001\right)$. The presence of farms had a significant negative effect ( $\mathrm{t}$ value $=-4.0, \mathrm{df}=32, \mathrm{~B}=-1.7 \pm 0.44$, $\mathrm{p}<0.001)$ while presence of poachers' sheds had a significant positive effect $(\mathrm{t}$ value $=3.6, \mathrm{df}=32, \mathrm{~B}=11.3 \pm 3.11$, $\mathrm{p}<0.001)$ on the encounter rate of species. The number of species encountered in the study area was affected significantly ( $R$ $\left.{ }_{2}=0.37, \mathrm{df}=31, \mathrm{p}<0.01\right)$ by some anthropogenic activities. These effects were both positive and negative.

Logged wood (which is evidence of habitat degradation) was seen to have a significant negative effect on number of species encountered $(\mathrm{t}$ value $=-2.6, \mathrm{df}=$ $32, \mathrm{~B}=-0.2 \pm 0.08, \mathrm{p}=0.013)$.

The presence of trails on the other hand was seen to have a significant positive effect on the number of species encountered $(\mathrm{t}$ value $=2.8, \mathrm{df}=32, \mathrm{~B}=0.3$ $\pm 0.12, \mathrm{p}=0.007)$.

\section{Primate Encounter Rate}

Anthropogenic activities from identified threats showed no significant effect on the abundance of primates and their signs (Overall model, $\mathrm{R}_{2}=0.40, \mathrm{df}=$ $32, \mathrm{p}=0.188)$. Active logging activities measured by the number of chainsaw machines heard had no significant effect on the encounter rate of primate species and their signs ( $\mathrm{t}$ value $=-1.3$, df $=32$, $\mathrm{B}=-1.0 \pm 0.74, \mathrm{p}=0.17)$ and habitat degradation measured by logged wood $(\mathrm{t}$ value $=-1.5, \mathrm{df}=32, \mathrm{~B}=-0.1 \pm 0.12, \mathrm{p}=$ 
0.13), although showing a negative trend, was not significantly correlated with encounter rate of primate species.

However the number of primates species encountered was probably affected (Overall model $\mathrm{R}_{2}=0.3273$, df $=31$ and $\mathrm{p}=0.013)$ by the month of survey ( $\mathrm{B}=-0.05 \pm 0.03, \mathrm{p}=0.09)$, logging activities ( $\mathrm{t}$ value $=-1.6, \mathrm{df}=32, \mathrm{~B}=-$ $0.04 \pm 0.02, \mathrm{p}=0.11)$ and the presence of trails ( $\mathrm{t}$ value $=3.2, \mathrm{df}=32, \mathrm{~B}=0.13$ $\pm 0.04, \mathrm{p}<0.01)$.

\section{Discussion}

We strategically surveyed the western and eastern part of the Oban Division of CRNP and assessed primate, mammal, and some large bird species relative abundance, identified threats associated with the area, and assessed the threats in relation to encounter rate of the surveyed faunal groups encountered.

Thirteen major potential threats were identified which were either classified as direct threats to species or indirect threat to species habitat. Direct threats to species included: spent cartridges, gunshot heard, poachers shed, snares, individuals encountered, and other evidence of human presence. These threats are designated as direct because they are known to affect species richness and abundance. Indirect threats included: farms, logged wood, chainsaw machine heard, foot/tractor trails and collection of Non-Timber Forest Products. Unlike direct threats, the indirect threats identified are associated with habitat degradation which likely affects species richness and abundance indirectly. Four threats were identified as important threats (farms, logged wood, spent cartridges and snares) in regards to the highest frequency having an encounter rate $>0.50$ per $\mathrm{km}^{2}$, predicting faunal species encounter rates and characterising differences in threat levels between the two parts (Oban east and Oban west) of the area.

\section{Oban East and Oban West}

The differences in overall disturbance rate assessed by the encounter rate of identified threats between the different parts (East and West) of the Oban suggest a probable difference in the protection effort between the different parts of the area; hence the level of anthropogenic activities differs. Looking at the four threats identified as important probable threats, logging and hunting using snares showed a non-significant difference between the two areas with the Oban East having a higher variation; while hunting pressure assessed from the abundance of spent cartridges and farms showed a clear significant difference with the Oban East having a higher rate than Oban West. This is probably due to the fact that the Oban forest being characterized by different undulating altitudes (BirdLife, 2012; Eniang et al., 2008) would naturally vary in species distribution; hence some species are likely to occur in specific parts based on their requirement. Hunting pressure will more likely be higher in regions with higher species richness. As such, species that are habitat specific in the region could massively decline or be lost if the area at which they occur happens to have high hunting pressure and low or no protection enforcement.

However, if these differences exist as a result of differing levels of protection enforcement between different parts of the Oban by CRNP management, this then renders some areas more vulnerable 
to disturbance. Members of local communities living around and within would likely be aware of these differences. Hence most illegal disturbance and exploitation in some in less protected areas will go unchecked and at higher frequencies.

Top priority regarding protection enforcement activities needs to focus on areas identified to have a high encounter rate of identified threats. Members of local communities living in close proximity to such areas are the most likely natural exploiters within such areas and are likely responsible for the associated disturbances.

\section{Presence of Farms and the Conservation Implication to the Oban}

One of the main drivers of tropical forest loss in Nigeria is forest destruction for agricultural purposes. Bisong (2003), in a study carried out around settlements in the Oban Division CRNP and other protected areas in Cross River state, identified that members of local communities in the region have a preference for virgin forest for cultivation over their old farms as it brings about a higher crop yield. This explains the emergence and existence of farms in the study area as well as other protected areas. Factors such as population growth, increase in family sizes, increase in market prices of cash crops factors and lower yield from domestic farmland are responsible for an increase in the demand to clear more virgin forest for farms (Bisong, 2003). It might be expected that the farms we encountered in the study area would be small and of a subsistence type. This was not the case however as farms encountered were mostly, cocoa, banana, plantain farms. These are crops grown on a commercial scale as the region is known the export of these crops on a large commercial scale to different urban cities within the country. With an increase in demand for cash in crops (Bisong, 2003), an increase in population around the Oban is expected which will further increase the need to clear more virgin forest of which the remaining fragments are found within the borders of CRNP.

The presence of farms in the Oban showed a significant negative effect on the encounter rate of species. These farms seem to degrade suitable natural habitat for species leading to the low encounter rate of species. If unchecked this trend will probably continue and lead result in extirpation of sensitive and habitat specific species as well as imperiled species like the Nigeria-Cameroon chimpanzee from the area.

\section{Logging and its Conservation implication to the Oban}

Logging has been recognized as a fundamental threat to forests, a range of programs are being established at an international scale to address it (Bowles et al., 1998). We observed that trees were selectively logged based on the size and timber quality. Taller trees of about $20 \mathrm{~m}$ and above were logged, chopped into planks and transported out of the forest. Being a protected area where any form of logging is illegal, selective logging of this nature is known to leads to the creation of tracks that are usually unsuitable for a protected area (Laurence, 2001). This sort of logging known as selective logging is a poorly managed and results in a lot of environmental damage (Laurence, 2001). Logging in the Oban is likely to have multiple detrimental effects on species richness and diversity as it alters the habitat and 
creates an opportunity for other disturbances and threats. Detrimental effects of logging would include forest gaps where trees have been logged and the creation of paths/trails to transport the logged wood out which will result in a network of roads through the forest. Such tracts are known to eventually serve as access routes for other anthropogenic activities (Kühl et al., 2008) such as hunting, snaring as well as clearing more areas for farms. During the survey, logging activities also showed a significant negative effect on the species encounter rate confirming it as an important threat to the CRNP (BirdLife, 2012). Logging and its associated effect (road network) is a well-known indirect threat to primates (Kühl et al., 2008) as well as other species in most forests.

\section{Hunting and the conservation implication to the Oban}

Evidence of hunting during this survey was identified and assessed by the presence and the number of the following threats; spent cartridges, snares, gun shots heard, carcases encountered (bush meat), and poachers sheds encountered. Spent cartridges and snares were however the most frequently encountered and the occurrence of these correlated negatively with the encounter rate of faunal species.

Hunting is well known to be one of the traditional types of exploitation of natural resources by communities living around the Oban (BirdLife, 2012). However, with the designation of the area as a protected area, hunting and other exploitation of natural resources in the Oban was made illegal by the Nigerian Government (Eniang et al., 2012).

Species of conservation concern such as the Nigeria-Cameroon chimpanzee, Red-rumped putty-nosed monkey,
Allen's Galago's and the African grey parrot are found in the Oban. These species amongst many others are highly exploited for bush meat and the pet trade (Eniang et al., 2008). However, identification of the direct threats mentioned above in the Oban and specifically high encounter rate of spent cartridges suggests that some species are being exploited at a high rate and it calls for attention and conservation action so as to preserve species from becoming locally extirpated from the area.

\section{Effect of Identified threat on Primates} species

Populations of primate species are generally known to be faced with ongoing threats, (Mittermeier et al., 2006) directly through hunting and indirectly through habitat loss and degradation (Kühl et al., 2008). However, from this study, encounter rates of primates did not seem to be significantly affected by some of the identified threats, though some threats such as logging showed a negative trend. Anthropogenic effects on primate population may be delayed (Mammides et al., 2008) and indeed initially habitat degradation and disturbance may increase visibility and so apparent abundance of some species may seem unaffected. For example, a study that took place in Kibale showed that it took more than seven years before the impact of logging activities at different levels reflected in a decline in the densities of monkeys (Chapman and Lambert, 2000). All previous studies suggest that primates are threatened in the areas facing habitat destruction and hunting. We have evidence of these threats in the area of the Oban. The lack of strong evidence in our study to link these threats to primate 
abundance should not be seen as evidence for lack of effect, but instead of a reflection of the difficulty of establishing such a link when already most of the primates are affected by such threats.

\section{Conclusion}

While it has been recognized that enforcement of protection in the Oban needs to be strengthened to ensure a reduction in human-induced disturbances, results from this study were able to identify the continuation of these threats and the continued need for increased enforcement of the legal status of the area. We also provide some specific suggestions to inform management and conservation decisions for the protection of this important biodiversity area.

The threats identified and their frequencies regarding encounter rate per $\mathrm{km}^{2}$ suggests that the level protection in one of the largest and the most biodiversity rich regions in Nigeria (Eniang et al., 2008) needs to be reviewed. Top priority should be given to this area regarding research to change its present status as a relatively neglected area with few extensive studies (Demey et al., 2003; Oates et al., 2002).Urgent actions are needed to reduce the rate of habitat loss through farming and logging activities in the area as well as hunting which is a direct threat to faunal species richness and abundance of the area. We suggest that protection measures be improved so as to mitigate biodiversity loss in the region and allow for recovery of imperil species occurring in the region.

\section{Acknowledgement}

Conservation Leadership Programme (CLP) and the Rufford Small Grants
Foundation for funding this work. Cross River National Park (CRNP), Nigeria National Parks (NNP), A P Leventis Ornithological Research Institute (APLORI) University of Jos Nigeria and Wildlife Conservation Society (WCS) Nigeria for logistical and technical support. Prof Will Cresswell, St Andrews University Scotland and Students Conference on Conservation Science (SCCS), Cambridge England for mentoring. Leaders and members of the Oban hills and CRNP surrounding local communities for their cooperation.

\section{References}

Aguirre, A.A., Ostfeld, R.S., Tabor, G.M., House, C. and Pearl, M.C. (Eds) (2002). Conservation Medcine Ecological Health in Practise. Oxford University Press, Inc New York. Pp253.

BirdLife International (2012). Important Bird Areas factsheet: Cross River National Park: Oban Division. Downloaded from http://www.birdlife.org on 12/04/2012.

Bisong, F.E. (2003). Deforestation motivators by small farmers in common and protected lands in South Eastern Nigeria: A Factor Analytic Approach. Mathematics Connection, 3:1-23.

Bowles, I.A., Rice. R.E., Mittermeier, R.A. and da Fonseca, G.A.B. (1998). Logging and Tropical Forest Conservation. Science: 280 (5371), 1899-1900.

Corlett, R and Primark, R.B (2010). Tropical Rainforest: An Ecological and Biogeograhpical Comparism. $2^{\text {nd }}$ Edition. Wiley-Blackwell Publishing, MA. Rainforest on each continent 
have distinct assemblage of animal and plant species.

Chapman, C.A. andLambert, J.E. (2000). Habitat alteration and the conservation of African primates: case study of Kibale National Park, Uganda. Am. J. Primatol. 50: 169185.

Demey, R.F., Dowsett-Lamaire and Dowsett, R.J. (2003) Notable bird observation from Nigeria including first record of Spot-breasted Ibis Bostrychiarara and Yellow Longbill Macrosphencus flavicans. Malimbus , 25:85-94.

Eniang, A.E., Eniang, M.E and Akpan, C..E (2008). Bush Meat Trading in The Oban Hills Region of SouthEastern Nigeria: Implication for Sustainable Livelihood and Conservation. Ethiopian Journal of Environmental Studies and Management. 1(1):70-83.

Kühl, H., Maisels, F., Ancrenaz, M. and Williamson, E.A. (2008). Best Practice Guidelines for Surveys and Monitoring of Great Ape Populations. Gland, Switzerland: IUCN SSC Primate Specialist Group (PSG). 32 pp.

Laurence, W.F (2001) Tropical Logging and Human Invasion. Conservation Biology, 15(1):1-4.

Mammides, C., Cords, M., and Peters, M.K (2008). Effects of habitat disturbance and food supply onpopulation densities of three primate species in theKakamega Forest, Kenya. Afr. $J$. Ecol., 47: 87-96.

Morgan, B. J., Adeleke, A., Bassey, T., Bergl, R., Dunn, A., Fotso, R. and Mbah, G. (2011). Regional action plan for the conservation of the Nigeria-Cameroon chimpanzee (Pan troglodytes ellioti). IUCN/SSC
Primate Specialist Group and Zoological Society of San Diego.

Mittermeier, R.A., Valladares-Padua, C., Rylands, A.B., Eudey, A.A., Butynski, T.M., Ganzhorn, J.U., Kormos, R., Aguiar, J.M. and Walker, S. (2006). Primates in peril: the world's 25 most endangered primates 2004-2006. Prim. Conserv. 20: 1-28.

Myers, N., Mittermeier, R.A., Mittermeier, C.G., DaFonseca, G., A.B. and Kent, J. (2002). Biodiversity hotspots for conservation priorities. Nature, 403:853-845.

Oates, J.F., Bergl, R.A. and Linder, J.M. (2004). Africa's Gulf of Guinea Forests: Biodiversity Patterns and Conservation Priorities. Advances in applied Biodiversity Science: No.6. Centre for applied Biodiversity Science@ CI. Wildlife Conservation Society.

Oates, J., Groves, J.S., Bergl, R., Dunn, A., Nicholas, A., Takang, E., Imong, I., Fotso, R., Nkembi, L., and Williamson, L. (2007). Regional Action Plan for the conservation of the Cross River Gorilla (Gorilla gorilladiehli). IUCN /SSC Primate Specialist Group and Conservation International, Arlington, VA, USA.

Parrish, J.D., Braun, D.P. and Unnasch, R.S. (2003). Are we conserving what we say we are? Measuring ecological integrity within protected areas. BioScience, 53(9): 851-860.

Secretariat of the Convention on Biological Diversity (2010). Forest Biodiversity-Earth's Living Treasure. Montreal, 48 pages.

Sechrest, W.W and Brooks, T.M (2002). Biodiversity -Threats, encyclopedia of life sciences / \& 2002 Macmillan Publishers Ltd, Nature Publishing Group / www.els.net 